\title{
QUEBRA DE MÁXIMAS CONVERSACIONAIS NAS TIRINHAS DO ARMANDINHO: UMA POSSIBILIDADE METODOLÓGICA PARA O ENSINO EXPRESSIVO DA LÍNGUA PORTUGUESA
}

\author{
Breaking Conversational Maxims \\ in Armandinho Comic Strips: \\ A Methodological Possibility for an \\ Expressive Brazilian Portuguese Teaching \\ Rompimiento de máximas conversacionales \\ en cómics de armandinho: una posibilidad \\ de metodología para la enseñanza \\ expresiva de la lengua portuguesa
}

\author{
Hilma Ribeiro de Mendonça Ferreira* \\ *Universidade do Estado do Rio de Janeiro, Colégio de Aplicação, Rio de Janeiro, RJ, \\ Brasil Silvia Adelia Henrique Guimarães** \\ **Secretaria Municipal de Educação do Rio de Janeiro, Rio de Janeiro, RJ, Brasil
}

\begin{abstract}
Resumo: O objetivo central da investigação é contribuir para os estudos do texto, com pauta: 1) na teoria dos gêneros como práticas sociais; 2) na sobreposição tipológica possível nos gêneros; e 3) na relação entre gênero e intencionalidade, pelo viés da Pragmática. Especificamente, o artigo investiga como quatro alunos do nono ano entenderiam a quebra de máximas conversacionais como recurso expressivo para a geração de humor; e, ainda, se perceberiam a carga argumentativa desses diálogos de base narrativa - análise realizada em três tirinhas do Armandinho. Com base no paradigma interpretativista, procede à análise, instrumentalizado pelos atos da fala e pela quebra da máxima conversacional de modo. Os resultados apontam que os estudantes compreendem que a quebra da máxima de modo constrói o humor das tirinhas; mas não demonstram compreender que o fenômeno linguístico serve, também, à argumentatividade implicada nas falas.
\end{abstract}

Palavras-chave: Sobreposição tipológica. Máxima conversacional. Gênero. Ensino.

\begin{abstract}
The main objective of this paper is to contribute to text studies based on 1) Genres Theory as social practices; 2) a possible typological overlap in genres; and 3) on the relation between genre and intentionality through a pragmatics approach. Particularly, we investigate if four ninth grade students would understand the conversational maxims break as an expressive resource to produce humor; and if they would perceive the argumentative content of these narrative-based dialogues. This analysis takes part into three comic strips featuring Armandinho, the questioning boy. Sustained on the interpretivist paradigm, we do a linguistic data analysis, instrumentalized by discussions about speech acts and the breaking of the conversational maxim of manner. The results indicate that those students understand that the breaking of the maxim of manner constructs the humor of the comic strips; nevertheless, they do not seem to comprehend the linguistic phenomenon also as a participant in the argumentativeness implied in the lines.
\end{abstract}

Keywords: Typological overlap. Conversational maxim. Genre. Teaching.

* Professora Regente no Colégio de Aplicação da UERJ. ORCID: https://orcid.org/0000-0002-2593-5940. E-mail: hilmaribeiro1976@gmail.com.

** Professora Regente na Secretaria Municipal da Educação do Rio de Janeiro. ORCID: https://orcid.org/0000-0002-8208-0133. E-mail: sguimaraes05@hotmail.com. 
Resumen: El objetivo central de la investigación es contribuir con los estudios de texto, por medio de los temas: 1) en la teoría de géneros como prácticas sociales; 2) en la sobreposición de tipos posibles en los géneros; y 3) en la relación entre género e intencionalidad, desde la visión de la Pragmática. En concreto, hemos investigado cómo cinco estudiantes de noveno grado entendieron el rompimiento de las máximas conversacionales como recurso expresivo a la generación del humor; $y$, sin embargo, si iban a entender la carga de argumentación de estos diálogos de base narrativa - análisis realizado en tres cómics de Armandinho. Basados en el paradigma interpretativo, el análisis es hecho a través de los actos de habla y el rompimiento de la máxima conversacional de modo. Los resultados muestran que los alumnos comprenden que la violación de la máxima de modo construye el humor de los cómics; pero no demuestran la comprensión de que el fenómeno lingüístico también sirve a la argumentación en las hablas.

Palabras clave: Sobreposición de tipos. Máxima conversacional. Género. Enseñanza.

\section{INTRODUÇÃO}

As últimas décadas têm sido marcadas por grandes desafios na educação brasileira, tanto nos aspectos políticos quanto nos paradigmáticos. No âmbito político, porque o Brasil responde a necessidades de inclusão, sejam físicas (construção de unidades escolares, acesso e permanência dos estudantes via transportes e alimentação, disponibilização de material didático, etc.), sejam ideológicas (formação de professores, mudança da noção do acesso, etc.) (LDB 9394/96). No âmbito paradigmático, porque as concepções pedagógicas estão engendradas em teóricos que entendem a língua como ação e o texto como forma de participação no mundo (SOARES, 2006; KOCH, 1995).

Isso posto, atividades com gêneros textuais vêm ganhando amplo espaço nas aulas de língua materna. Nesse sentido, e para contribuir com as pesquisas que já defendem a noção de gênero como forma de desenvolvimento linguístico-discursivo do estudante (VARGAS; MAGALHÃES, 2011; RIBEIRO, 2013), no presente trabalho concentramonos em um gênero amplamente difundido na sociedade, a tirinha, por meio dos mais diversos suportes: a internet, o livro impresso, os jornais e revistas, dentre outros.

Filiadas ao paradigma qualitativo (ALVEZ-MAZZOTTI, 1999; DENZIN; LINCOLN, 2006), propomos apresentar e discutir uma atividade escolar que se deteve na quebra das máximas conversacionais propostas por Grice (1984). Para a elaboração da atividade, selecionamos três tirinhas do Armandinho e solicitamos aos participantes uma análise dos diálogos entre o Menino Questionador e seus interlocutores. Objetivamos, com a atividade, observar como estudantes do nono ano do Ensino Fundamental entenderiam a quebra proposital dessas leis conversacionais como recurso expressivo para a geração de humor; e, ainda, se eles perceberiam a carga argumentativa desses diálogos.

Pelos objetivos elencados, duas teorias linguísticas, de escopo pragmático, foram caras ao trabalho e, estrategicamente, as interseccionamos na análise dos dados: o estudo dos atos de fala, desenvolvido por Austin (1962) e Searle (1969), e as regras ou máximas conversacionais evidenciadas em Grice (1984) no contexto da Pragmática Conversacional. Detivemo-nos, ainda, nas teorias de tipologia e de gêneros textuais, que contribuem para a perspectiva de contextualização do texto-ação (MASCUSCHI, 2008). 


\section{SOBREPOSIÇAO TIPOLÓGICA, GÊNEROS TEXTUAIS,ATOS DE FALA E MÁXIMAS CONVERSACIONAIS: UMA CONVERGÊNCIA POSSÍVEL}

$\mathrm{Na}$ perspectiva interacionista, um texto responde às situações específicas de enunciação e, portanto, materializa uma infinidade de gêneros. Além disso, responde às intenções dos sujeitos envolvidos na comunicação, os quais indiciam as sequências tipológicas neles realizadas (MARCUSCHI, 2010; BRONCKART, 2012).

Nesse caso, a noção de tipologia, a partir das sequências textuais (narrar, argumentar, expor, descrever e injungir), será definida por sua natureza linguística, contando com a análise de categorias linguísticas tais como léxico, sintaxe, tempos verbais, relações lógicas e estilo (MARCUSCHI, 2007). Para além dessa composição material, concordamos que determinada sequência tipológica pode ocorrer de forma majoritária, mas não necessariamente exclusiva em um determinado texto, tornando-o um tipo textual hibridizado - que Marcuschi (2007) denomina heterogeneidade tipológica.

Consideramos que a complexidade da tipologia textual não se restringe a seus modelos formais, tampouco a sua funcionalidade sociocomunicativa, mas abrange, também, o aspecto subjetivo de sua construção linguística. Neste sentido, nos últimos anos vários estudiosos do texto vêm confirmando a relação entre as tipologias textuais e as formas enunciativas dos falantes, de acordo com as intenções desses locutores, em relação ao ato comunicativo. Contudo, se considerarmos o modo como os conteúdos informativos são transmitidos a seus destinatários, entenderemos que os tipos textuais não preconizam apenas os desejos desses falantes, mas são, também, formas de ação adequadas às intenções dos falantes, numa abordagem pragmática, nas diferentes sequências tipológicas; ou seja, os tipos textuais, em relação aos atos de fala que a eles subjazem, podem transmitir a totalidade de intenções cabíveis a esses atos de fala (SILVA, 1999; SOUZA, 2012). Trata-se, portanto, de um ponto teórico que interessa ao estudo, tendo em vista que a tirinha é um gênero que apresenta uma base tipológica narrativa, mas pode conter traços de outras bases retóricas - no caso específico das tirinhas do Armandinho, a sobreposição tipológica ocorre pela interseção entre a base narrativa e a argumentativa.

Ademais, o componente pragmático da linguagem apresenta-se relevante para se pensar a aplicabilidade da hibridização tipológica, especialmente por extrapolar a análise estrita dos enunciados, concentrando-se na intencionalidade dos sujeitos produtores. As teorias de base pragmática, historicamente, assentam-se em duas grandes vertentes, que culminaram no que se entendeu por "virada pragmática". A pragmática, então, constituise em pressuposto importante para: a teoria dos atos de fala e a Pragmática Conversacional, perspectiva teórica inaugurada por Paul Grice, na qual as máximas conversacionais funcionam como regras implicadas pelo que ele chamou de Princípio Cooperativo. Estas duas linhas da Pragmática constituem as bases para a análise que propomos neste artigo.

Quanto à teoria dos atos de fala, John Austin (1962) afirma que, mediante suas necessidades interpessoais, os interagentes atuam, por meio da língua, com base nos diferentes recursos linguísticos disponíveis. Por isso é pertinente refletir sobre sua aplicabilidade ao gênero tirinha, sobretudo sobre a obra do cartunista Alexandre Beck, socialmente tão presente, hodiernamente, especialmente em atividades pedagógicas. 
A teoria dos atos de fala assenta-se sobre as diferentes possibilidades intencionais dos falantes, detectando o componente ilocucionário, a partir do entendimento de determinado enunciado como munido de não apenas uma função linguística, mas três. É sabido que, em um primeiro momento, Austin diferenciou dois tipos de enunciados, de acordo com o tipo de verbo apresentado: os constativos (que determinariam ações comunicativas, como relatos ou descrições) e os performativos (que resultariam da forma como o ato locucionário é interpretado pelos interlocutores). Por isso, a partir da teoria dos atos de fala por ele concebida, toda a representação enunciativa está no plano do proposicional, que vem a ser o primeiro plano, e tem uma intenção, o que configura o segundo plano. O terceiro plano ou nível de fala, para o autor, é o efeito dessa intencionalidade no interlocutor. Para sua aplicabilidade, Austin (1962) designou esses três planos da seguinte forma: $1^{\circ}$ ) o locucionário (proferir sentença, transmitir informação); $2^{\circ}$ ) o ilocucionário (informar, fazer um pedido, uma advertência etc., expressões que têm certa força convencional); e $3^{\circ}$ ) o perlocucionário (o que se quer conseguir por dizer algo, como convencer, persuadir, etc.). Essas três dimensões visam demonstrar como um mesmo modo de organização discursiva pode ser analisado, de acordo com seus campos de atuação. ${ }^{1}$

A partir da vertente teórica inaugural de Austin (1962), Searle (1981) desenvolve alguns conceitos que contribuem para uma metodologia dessa teoria, sistematizando categorias pragmáticas mais conhecidas, que são a da força ilocutória, a dos atos de fala indiretos e a das diferentes categorias de atos de fala (SEARLE, 1969) - conceitos estes que se destacam das obras de Austin (1962) por apresentar mais rigor científico. ${ }^{2}$

De acordo com Searle (1969), ao pronunciar uma frase o falante imporá certa "força ilocutória" ", que refletirá a intenção do locutor do texto ao pronunciar uma sentença, nas diferentes situações comunicativas. Ela diz respeito, portanto, não à materialidade linguística em si, mas à natureza do ato de fala. Desta forma, um enunciado poderá assumir forças ilocutórias diferentes conforme o interesse dos falantes, como "pedido", "afirmação", "declaração", "ameaça”, "ordem”, etc.

O teórico mostra, por conseguinte, que as "forças ilocutórias" geram diferenças de sentido interpretativo dos enunciados. Segundo Searle (1981, p. 43), "o marcador de força ilocucional indica o modo pelo qual é preciso considerar a proposição, isto é, qual será a força ilocucional a atribuir à enunciação [...] ou qual é o ato ilocucional realizado pelo falante quando profere a frase."

A partir da força ilocucionária, podemos inferir que o conceito de "atos de fala indiretos", que tem sido divulgado, hodiernamente, é um tipo de ato realizado com características típicas de outro tipo de ato, como nas perguntas retóricas, ou nas frases declarativas que pressupõem um pedido, por exemplo. $\mathrm{O}$ ato de fala indireto é compreendido a partir do propósito discursivo do locutor do texto e deverá ser inferido quando os interlocutores encontram-se engajados na manutenção da comunicação. Além disso, visa atender a peculiaridades estilísticas ou discursivas de certa composição textual.

\footnotetext{
1 Nesta fase, desfaz-se o lugar inicial de suas investigações, quando propunha a dicotomia entre os enunciados que promoveriam ação e os que não a promoveriam.

${ }^{2}$ Destacamos, entretanto, que, no aspecto acionista da linguagem, a teoria de Austin tem mais proeminência do que a de Searle (RAGAJOPALAN, 2010). De forma que Searle não "deu continuidade" à teoria inaugurada por Austin, mas ele, de fato, a sistematizou, dando um viés científico mais denso.

${ }^{3}$ Essa "força ilocutória” resgata o segundo plano, o ilocucionário, proposto por Austin (1962).
} 
Para além dessa verificação dos atos de fala indiretos, Searle (2002) classifica os atos de fala em cinco grupos, estudados a partir de diferentes planos: de ordem psicológica, filosófica e pragmática. Trata-se de categorias identificadas de acordo com suas características interlocutivas, que configuram as designações "assertivas", "diretivas", "compromissivas", "expressivas" e "declarações". De acordo com as categorias discriminadas, os atos de fala mostrarão ações diferenciadas, que se assemelham conforme a postura do falante/ouvinte, durante as trocas verbais. Fazemos o seguinte resumo dessas categorias: a) nos atos assertivos, os falantes comprometem-se a afirmar algo como sendo falso ou verdadeiro e, em contrapartida, os ouvintes assumem, ou não, determinado conteúdo como sendo falso ou verdadeiro; b) nos atos de fala diretivos, os falantes procuram fazer com que o ouvinte realize determinada tarefa, que será, ou não, realizada; c) nos atos de fala compromissivos, os falantes propõem-se a realizar algo que será passível da crença ou não do ouvinte do compromisso assumido pelo falante; d) nos atos de fala expressivos, o falante demonstra a emotividade derivada de algum fator externo ou interno, que será compartilhado ou não pelo ouvinte; e e) nos atos de fala declarativos, o locutor produz um enunciado que modifica uma situação externa, que será observada pelo ouvinte (SEARLE, 2002).

Integramos, neste ponto, outro aspecto teórico: acreditamos que a associação da teoria dos atos de fala com os tipos textuais contribui para a análise do desencadeamento das ações segundo a intencionalidade dos falantes, visto que uma sequência tipológica é, em realidade, a configuração do desejo dos indivíduos ao contar uma história, argumentar ou injungir, por exemplo. Sobre isso, ressaltamos a existência de estudos importantes sobre a composição material dos enunciados, como os desenvolvidos por Adam (2011) e Bronckart (2012), ao estipular a noção de "sequências tipológicas"; ou os apontados por Weinrich (1968) e Travaglia (1999), ao investigar o papel dos tempos verbais na composição textual dos tipos textuais. Ambos os enquadres teóricos podem se interseccionar numa análise linguística de cunho pragmático/textual dos enunciados.

Autores como Weinrich e Travaglia debruçam-se sobre a abordagem de que o "tipo textual figura como uma noção que se define pela determinação das relações internas da organização textual do discurso concretizadas no texto" (SILVA, 1999, p. 102). Todavia, acreditamos que a análise das tipologias pela visão pragmática pode contribuir como viés de análise comunicativo relevante para a aplicação dos estudos tipológicos na sala de aula. Além disso, ressaltamos a contribuição da "Teoria das Máximas Conversacionais" na análise da sequência tipológica, pois dimensiona o engajamento dos interlocutores ao indicar a existência do "princípio de cooperação". Por isso, nos detemos, nesse momento, na concepção teórica de Grice (1982).

A Teoria das Máximas Conversacionais postula que os indivíduos fazem esforços cooperativos para que os sentidos sejam eficazmente interpretados. Nessa perspectiva, o filósofo Paul Grice (1982) defende haver duas dimensões de análise conversacional: a dimensão do "dito" e a do que pode vir a ser "assumido", durante as trocas verbais. Para o autor, o que é "dito" pode tornar-se muito diferente do que vem a ser "implicado". Isso porque haverá certas "implicaturas" que mensuram quebras no que Grice (1982) designou como "máximas" da conversação. Essas máximas conduzem a postura comunicativa, de modo a formar os sentidos pelo que é transmitido. Se, para Austin (1962), dizer é fazer, para Grice (1982) o que é dito difere do que é assumido. Ambos, contudo, partem de uma centralidade intencional e pragmática da linguagem. 
Paul Grice (1982, p. 86) afirma que há uma grande regra conversacional em que os interactantes devem engajar-se para fazer com que se torne efetiva a "contribuição conversacional tal como é requerida, no momento em que ocorre, pelo propósito ou direção do intercâmbio conversacional em que você está engajado". A partir dessa grande regra, o autor subdivide as categorias em da "quantidade", da "qualidade", da "relação" e do "modo", que pressupõem acordos implícitos que regem a conduta dos indivíduos, conforme o quadro 1, a seguir, baseado na teoria ora referenciada.

\begin{tabular}{|l|l|}
\hline QUANTIDADE & $\begin{array}{l}\text { Relaciona-se à quantidade de informação a ser fornecida } \\
\text { Faça com que sua contribuição seja tão informativa quanto o requerido; } \\
\text { Não faça sua contribuição mais informativa do que é requerido. }\end{array}$ \\
\hline QUALIDADE & $\begin{array}{l}\text { Supermáxima: "Trate de fazer uma contribuição que seja verdadeira” } \\
\text { Não diga o que você acredita ser falso; } \\
\text { Não siga senão aquilo para que você possa fornecer evidência adequada. (...) }\end{array}$ \\
\hline RELAÇAO & $\begin{array}{l}\text { Seja relevante } \\
\text { MODO }\end{array}$ \\
& $\begin{array}{l}\text { Evite obscuridade de expressão; } \\
\text { Evite ambiguidades; } \\
\text { Seja breve (evite prolixidade desnecessária); } \\
\text { Seja ordenado. }\end{array}$ \\
\hline
\end{tabular}

\section{Quadro 1 - Máximas conversacionais de Paul Grice (1982)}

Fonte: Grice, 1982.

A quebra dessas máximas conversacionais ocorre quando os falantes deixam de cumprir o que elas designam, de modo a forçar os interlocutores a interpretarem sentidos diferentes daqueles que são ditos. ${ }^{4}$ Contudo, como a língua é ferramenta criativa para toda forma de comunicação, entendemos que, quando há quebras propositais dessas máximas, o texto, automaticamente, recebe o novo sentido pretendido (ALDROVANDI, 2015), sempre partindo do pressuposto de que a intencionalidade tem como foco os sujeitos participantes da interação. Por apresentar essas características teórico-metodológicas, a teoria das máximas de Grice (1982) auxiliam no estudo da intencionalidade materializada nos diálogos entre o personagem Armandinho e seus interlocutores, nosso escopo de análise; bem como na análise dos participantes da pesquisa sobre essa intencionalidade.

Além das noções pressupostas pelas teorias pragmáticas, importa ainda delimitar a noção de gênero textual, que subsidia nossa análise. Iniciamos pela distinção entre tipologia e gênero, que ainda gera alguma distorção. Enquanto a tipologia está definida em seu caráter retórico, os gêneros designam relações linguísticas concretas, definidas por propriedades sociocomunicativas. Trata-se de textos materializados em situações comunicativas recorrentes, que são relativamente estáveis, sendo, pois, tão diversas quanto o são as atividades humanas. Os diferentes gêneros estão, pois, aliados aos repertórios discursivos acionados nas trocas comunicativas (BAKHTIN, 1997).

\footnotetext{
${ }^{4}$ Ressaltamos que, embora os desdobramentos de seu estudo possam ser incorporados ao texto escrito, a teoria desenvolvida por Grice (1982) teve como corpora a modalidade oral, na qual o autor explicitou as condições gerais que regem a comunicação.
} 
Para os fins deste artigo, selecionamos o gênero Tirinha. Inserido no chamado hipergênero História em Quadrinhos, as Tirinhas são consideradas um gênero autônomo (RAMOS, 2013) e exemplificam uma escolha bastante recorrente nas salas de aula, seja de forma livre, pelos docentes, ou na forma de livros didáticos e afins. A opção pelo gênero tirinha pauta-se em aspectos linguísticos, como a multimodalidade; em aspectos sociais, como o interesse dos estudantes por esse gênero; e por aspectos discursivos, como a temática social proposta pelo autor de Armandinho.

Por sua caracterização teórica, a prática pedagógica por meio dos gêneros deve transcender a simples nomeação desses gêneros e o conhecimento de seus aspectos formais. Ela precisa agir no cerne da linguagem em ação, e, nesta, o falante reconhece o infinito repertório de gêneros oferecido nas interações. Por isso, em nível pedagógico, trabalhar por meio dos gêneros é não apenas decodificar conteúdos, mas desenvolver capacidade de mobilizar recursos de vários níveis para interagir sociodiscursivamente mediante uma competência sociocomunicativa (KOCH, 2011).

Acreditamos que trabalhar com gêneros, nessa perspectiva, contribui para o desenvolvimento e o arquivamento de experiências textuais dos alunos, possibilitandolhes a ampliação e a aplicação dessa experiência em outros contextos sociais. Nas palavras de Kleiman (2007, p. 12), "a participação em determinada prática social é possível quando o indivíduo sabe como agir discursivamente numa situação comunicativa, ou seja, quando sabe qual gênero do discurso usar".

Essa, inclusive, é a proposta encontrada nos PCNs e nas diversas pesquisas linguísticas no Brasil, principalmente as aplicadas, gerando a possibilidade de propor o desenvolvimento discursivo do aluno pelo enfoque da gramática e do texto como aspectos igualmente necessários à formação do estudante. Para assegurar isso, os PCNs propõem que as propostas didáticas se pautem em torno do texto, que considerem a diversidade desses textos que circula socialmente e que tornem possível "a análise crítica dos discursos para que o aluno possa identificar pontos de vista, valores e eventuais preconceitos neles veiculados" (BRASIL, 1998, v.1 p. 59).

Esse viés sociointeracional possibilita pesquisas cuja vertente teórica valorize, além dos aspectos gramaticais, os aspectos dinâmico e contextual da língua(gem).

\section{PERCURSO METODOLÓGICO}

Quanto à aplicação metodológica, este trabalho inscreve-se na abordagem qualitativa (ALVEZ-MAZZOTTI, 1999; DENZIN; LINCOLN, 2006), visto que analisa um corpus específico, a partir de uma pergunta, e não de hipóteses. Essa abordagem possibilita a análise de exemplos que aplicam e ampliam o entendimento do tema selecionado a partir de seu contexto de produção.

Esse design metodológico aplicou-se a uma atividade realizada por alunos de nono ano, para investigar como esses estudantes entenderiam o humor presente nas tirinhas de Armandinho; e como eles entenderiam a argumentatividade presente na sequência narrativa. Para compor o corpus da pesquisa, selecionamos as respostas de quatro alunos a uma atividade de compreensão textual sobre três tirinhas do personagem Armandinho. Como estratégia para o mapeamento, enumeramos as folhas de respostas de QMC_01 a QMC_04 (sendo, QMC: Quebra das Máximas Conversacionais). 
A atividade não teve cunho avaliativo e contou com concluintes do nono ano (Ensino Fundamental), com média de 14 anos de idade. O critério de participação foi o aceite voluntário ao convite, o que redundou em quatro participações. Trata-se de moradores da zona norte do Rio de Janeiro e estudantes da rede municipal, desde o primeiro segmento do ensino fundamental. São estudantes moradores de lugares periféricos, que contam com pouco acesso à cultura socialmente valorizada. Apesar da falta desse acesso, são sujeitos que apresentam interesse pelo saber formal e se destacam nos saberes escolarizados, o que resultou no aceite pela participação, marcado pelo desinteresse por notas, por exemplo. A relação dos estudantes com as pesquisadoras extrapolava a relação professor-aluno, pois não éramos os professores regentes da classe. Essa característica pode ter sublinhado uma relação distinta entre os participantes e a atividade: esta servia, socialmente, para uma pesquisa acadêmica, que serviria a algo, e eles o sabiam.

Os comandos das questões não foram previamente lidos, e os alunos realizaram a compreensão das tirinhas com a bagagem linguístico-discursiva de que dispunham. Essa estratégia objetivou relacionar as respostas dos estudantes como seres cognoscentes, com saberes já internalizados, sem a intervenção de um professor.

Os dados foram analisados em duas etapas distintas, sob a óptica da Pragmática. No primeiro momento, analisamos os diálogos entre o personagem Armandinho e seus interlocutores. Nessa etapa, procedemos à aplicação da teoria do ato da fala: a) detendonos no respaldo intencional (AUSTIN, 1962) e b) fazendo sua relação com a quebra da máxima do modo, segundo o estudo das máximas conversacionais (GRICE, 1984). No segundo momento, analisamos as respostas que os participantes deram às perguntas elaboradas sobre esses diálogos, conforme explicitadas na seção a seguir.

\section{ANÁLISE DOS DADOS E DISCUSSÃO DOS RESULTADOS}

Nesta seção apresentamos uma análise linguística das tirinhas, relacionando o respaldo intencional e a quebra da máxima conversacional de modo. Escolhemos, para isso, 3 textos e, em seguida, reproduziremos as perguntas que guiaram a leitura realizada pelos alunos, finalizando a seção com a interpretação dos resultados.

\subsection{ANÁLISE DA TIRINHA 1}
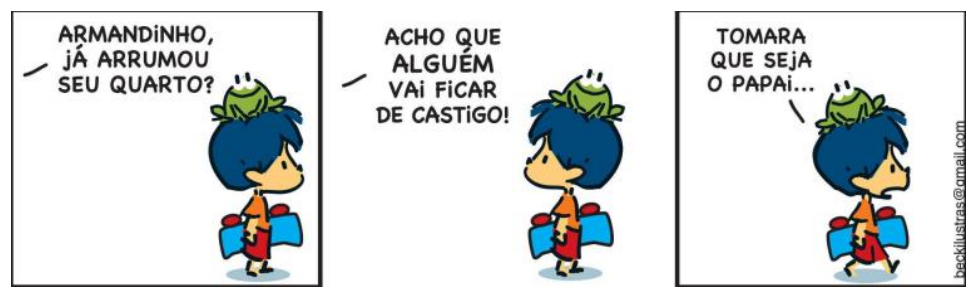

\section{Figura 1 - Tirinha 1}

Fonte: https://tirasarmandinho.tumblr.com/post/104193128309/tirinha-original 
Na tirinha 1, a primeira fala no quadrinho corresponde a um ato diretivo, que pressuporia, no perlocucionário, uma intimidação para o personagem atender ao comando. Já a segunda fala pressupõe dois atos de fala concomitantes: a constatação, correspondendo à assertividade, e o diretivo, correspondendo à intimidação. $\mathrm{O}$ elemento gerador do humor da tirinha, no último quadrinho, mostra a ausência do efeito da imposição no perlocucionário, destacando a dupla possibilidade ilocutória dos atos de fala. Isso se vê na resposta do ilocucionário, que interpreta a imposição como uma simples declaração.

Com o intuito de observar como os alunos perceberiam a intencionalidade (direção) discursiva, propusemos as questões apresentadas no quadro 2, no qual apresentamos, também, as repostas dos estudantes.

\begin{tabular}{|l|l|l|l|}
\hline Questão & $\begin{array}{l}\text { 1) Com a leitura dos dois } \\
\text { primeiros quadrinhos, que reação } \\
\text { você esperava de Armandinho, ou } \\
\text { que tipo de resposta? }\end{array}$ & $\begin{array}{l}\text { 2) Onde está o humor da } \\
\text { tirinha? Justifique. }\end{array}$ & $\begin{array}{l}\text { 3) Para que a história não tivesse } \\
\text { esse desfecho, o que a mãe do } \\
\text { Armandinho deveria ter dito? }\end{array}$ \\
\hline QMC_01 & Que ele fosse arrumar o quarto & $\begin{array}{l}\text { No 30 quadrinho. Em ele } \\
\text { achar que o pai que vai ficar } \\
\text { de castigo }\end{array}$ & $\begin{array}{l}\text { "E você que vai ficar de castigo, } \\
\text { se não arrumar o quarto" }\end{array}$ \\
\hline QMC_02 & $\begin{array}{l}\text { E de se esperar uma indignação de } \\
\text { Armandinho, pelo fato que ele iria } \\
\text { ficar de castigo }\end{array}$ & $\begin{array}{l}\text { Esta onde ele se refere } \\
\text { "tomara que seja o papai" }\end{array}$ & $\begin{array}{l}\text { "você vai ficar de castigo } \\
\text { Armandinho }\end{array}$ \\
\hline QMC_03 & Que ele fosse arrumar o quarto & $\begin{array}{l}\text { No terceiro quadrinho. Ele } \\
\text { achar que o pai vai ficar de } \\
\text { castigo e não ele. }\end{array}$ & $\begin{array}{l}\text { A mãe do Armandinho deveria } \\
\text { te sido mais direta e falado que } \\
\text { ele ficaria de castigo e não } \\
\text { "alguém". }\end{array}$ \\
\hline QMC_04 & Medo & $\begin{array}{l}\text { No último quadro, pois ele da } \\
\text { uma resposta inesperada. }\end{array}$ & "Você está de castigo" \\
\hline
\end{tabular}

\section{Quadro 2 - Respostas dos estudantes}

Fonte: Fragmentos dos enunciados elaborados pelos participantes da pesquisa.

As respostas referentes a essas perguntas indicam que os sujeitos da pesquisa compreenderam a fala da mãe como um ato diretivo, conforme QMC_03: "[esperava-se] Que ele fosse arrumar o quarto" e QMC_04: "Medo" (referindo-se à reação esperada). Apenas um dos participantes respondeu de forma diferente: (QMC_02) "E de se esperar uma indignação de Armandinho, pelo fato que ele iria ficar de castigo", resposta na fala da mãe como uma sentença, e não como uma ameaça que poderia ser revogada, caso o menino obedecesse. A resposta sugere que o participante não relaciona o segundo e o terceiro quadrinhos, tampouco o pronome "alguém" e "Armandinho".

As respostas mostram, ainda, que os alunos compreendem que o humor da tirinha reside na quebra da máxima do modo, afetando a "clareza", por parte da mãe (no segundo quadrinho), o que leva Armandinho a desconsiderar a imposição que lhe foi dirigida. Isso se vê em todas as respostas que compõem esta etapa do trabalho, conforme os excertos QMC_01: "No terceiro quadrinho. Ele achar que o pai vai ficar de castigo e não ele"; QMC_02: "Esta onde ele se refere "tomara que seja o papai"”. 
Os dados sugerem, principalmente, que os participantes percebem a importância das escolhas lexicogramaticais para a expressão/compreensão das intenções. Depreendese isso das respostas à terceira pergunta ("Para que a história não tivesse esse desfecho, o que a mãe do Armandinho deveria ter dito"), quando os participantes sinalizaram que a substituição do pronome indefinido por um definido desfaria a ambiguidade na fala da mãe. Exemplo disso se vê em QMC_03 "A mãe do Armandinho deveria te sido mais direta e falado que ele ficaria de castigo e não 'alguém"'.

De forma geral, a análise da atividade com a primeira tirinha revela que os participantes entenderam a confusão de sentidos que ocorre no texto. Mostra, também, que eles depreenderam essa confusão das escolhas linguísticas equivocadas, por parte da mãe, o que afeta a compreensão do garoto. Porém, os dados revelam que os participantes, de forma geral, não compreenderam a tentativa de convencer como parte inerente dessa narrativa. Os resultados apontam, pois, que os estudantes entendem a língua como interação necessariamente explícita, independentemente da intenção. Dessa primeira análise pode-se inferir que existe a necessidade de leitura de textos que exijam mais a habilidade dos estudantes em compreender a intimidação como ato de fala indireto, relacionado não à narração, mas à argumentação em si.

\subsection{ANÁLISE DA TIRINHA 2}
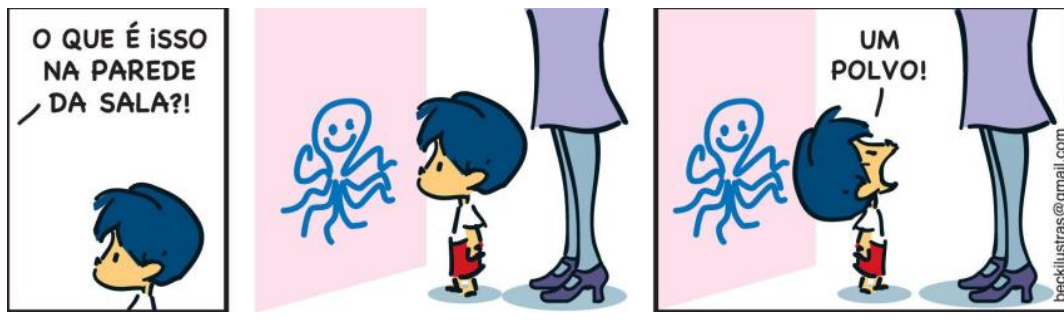

Figura 2 - Tirinha 2

Fonte: http://tirasarmandinho.tumblr.com/post/104193128309/tirinha-original

$\mathrm{Na}$ tirinha 2, o primeiro enunciado constitui a sobreposição das frases interrogativa e imperativa, explicitadas, linguisticamente, pelos sinais de interrogação e de exclamação. A fala da mãe, nesse caso, instaura a seguinte sequência: a) a injuntiva, marcada por seu questionamento, desejosa de uma resposta do menino que explicasse sobre o desenho, papel da frase interrogativa; e b) o tom mais incisivo da mãe, refletindo seu estado emocional no momento do proferimento, exigindo de Armandinho uma resposta para os rabiscos na parede, implicaria o uso da frase imperativa. Ambas as leituras sobre a função das frases do primeiro quadrinho respaldam a caracterização de uma sequência injuntiva, visto que tanto a pergunta quanto a imposição exigem do menino um posicionamento. A resposta de Armandinho, no último quadrinho, constitui resposta para a pergunta da mãe, cujo termo "isso" não é levado a cabo como sendo uma peripécia, mas como um simples desenho, no caso, um ser - "o polvo". 
No plano ilocucionário, ambas as frases impõem, no primeiro plano, atos diretivos, pois tanto o questionamento quanto a ordem exercitam, no interlocutor, um posicionamento. Porém, o diretivo implícito na frase imperativa pode indicar o ato expressivo, sobrepondo dois atos de fala no mesmo enunciado. Nesse caso, o menino responde apenas indicando o que estava desenhado, sem se posicionar de forma a acatar a pergunta e a ordem como sendo imposições da mãe sobre sua atitude. O que está em jogo, aqui, é a detecção do ilocucionário diretivo, e não o expressivo; e a ambiguidade provocada pela fala da mãe dá margem para o menino perceber o que precisa para não acolher a fala dela como ralha/imposição e sim como simples pergunta.

Para direcionar a leitura dos alunos para o campo das máximas conversacionais, elaboramos as questões apresentadas no quadro 3, no qual apresentamos, também, as repostas dos participantes.

\begin{tabular}{|l|l|l|l|}
\hline Respostas & $\begin{array}{l}\text { Questão resposta a mãe de } \\
\text { Armandinho esperava dele? }\end{array}$ & $\begin{array}{l}\text { Onde está o humor da } \\
\text { tirinha? }\end{array}$ & $\begin{array}{l}\text { Que pergunta a mãe de } \\
\text { Armandinho deveria ter feito, } \\
\text { para levá-lo à resposta } \\
\text { esperada? }\end{array}$ \\
\hline QMC_01 & $\begin{array}{l}\text { Nenhuma, pois era uma pergunta } \\
\text { retórica }\end{array}$ & $\begin{array}{l}\text { Na resposta do } \\
\text { Armandinho }\end{array}$ & “Que animal é esse?” \\
\hline QMC_02 & $\begin{array}{l}\text { Ela esperava que ele dissesse que } \\
\text { era apenas um desenho }\end{array}$ & $\begin{array}{l}\text { Esta quando o menino de } \\
\text { que o que esta na parede e } \\
\text { um polvo }\end{array}$ & “Quem fez isso na parede?" \\
\hline QMC_03 & Que é um desenho que ele fez. & $\begin{array}{l}\text { Ele responder que é um } \\
\text { polvo normalmente, } \\
\text { achando que não há } \\
\text { problema. }\end{array}$ & $\begin{array}{l}\text { Ela deveria ter perguntado “que } \\
\text { animal é esse?” }\end{array}$ \\
\hline QMC_04 & Ela esperava uma explicação & No último quadro & "Porque desenhou na parede?” \\
\hline
\end{tabular}

\section{Quadro 3 - Repostas dos estudantes}

Fonte: Fragmentos dos enunciados elaborados pelos participantes da pesquisa.

De modo geral, os alunos não reconheceram a força ilocucionária pressuposta pelo enunciado da fala da mãe, que incorpora atos de fala concomitantes (o diretivo, impondo; e o expressivo, denotando estado emocional). Essa constatação é percebida em quatro das quatro respostas, como QMC_01: "Nenhuma, pois era uma pergunta retórica" e QMC_02: "Ela esperava que ele dissesse que era apenas um desenho". Apenas QMC_04: "Ela esperava uma explicação" - aponta um teor argumentativo para a fala da mãe, o que sugere que os sujeitos, de forma geral, não elaboraram uma possibilidade argumentativa para perguntas indiretas - o que refletiria a dubiedade dos atos de fala, quando indiretos.

Apenas um participante sinalizou que a mãe deveria ser direta no aspecto inquiridor de sua pergunta. Trata-se, novamente, de QMC_04: “Porque desenhou na parede?". Nesse caso, percebemos a ausência de maturidade linguística dos alunos para interpretar sentidos que advenham do uso de atos de fala quando indiretos, que estipulam a ambiguidade, no caso da extrapolação da máxima do modo. Os demais participantes sustentaram um padrão de resposta que não relacionava a fala de Armandinho e uma quebra proposital para fins expressivos - neste caso, o humorístico. Vejam-se QMC_01 “Que animal é esse?”; e QMC_02: “Quem fez isso na parede?”. 
Apesar de contraditório, os sujeitos geradores do corpus entenderam que o humor da tirinha 2 reside na quebra de uma resposta mais abrangente, relacionada ao comportamento do menino. Contudo, os alunos sugeriram isso por caminhos diversificados. Enquanto um aluno apontou para a geração de humor de forma a generalizar a fala de Armandinho, conforme QMC_01 "Na resposta do Armandinho"; dois outros alunos associaram o humor à escolha linguística do personagem, relacionando-a ao polvo, conforme QMC_02: "Esta quando o menino de que o que esta na parede e um polvo". Além desses alunos, que, de forma geral ou específica, apontaram para a construção discursiva de Armandinho no tocante à geração de humor da tirinha, percebemos que um deles apontou para fora do texto, de modo a não citar a língua como mecanismo de construção expressiva: QMC_04: "No último quadro."

Nesse caso, acreditamos que a argumentatividade é obtida por meio de uma imposição, sobrepondo-se à sequência injuntiva, pois a personagem mãe do menino quer que ele responda à sua colocação, à sequência argumentativa. Essa última tipologia é verificável na medida em que, subjacente à imposição, também, há a tentativa de convencimento do erro do menino e que deve haver uma mudança de comportamento. Logo, sobrepõem-se: a) o linguístico, com a conjugação dos tipos frasais; b) o discursivo, pois essas frases indicam intenções que sugerem enunciados de diferentes projeções interpretativas, com isso, revelando ambiguidade; c) o textual, pois há uma sobreposição de tipologias; em um nível maior, a retratação dos fatos, que evidencia o papel da narração; a imposição inerente à fala, que denota a injunção; e o convencimento, burlado por Armandinho, que preconiza a argumentação.

\subsection{ANÁLISE DA TIRINHA 3}
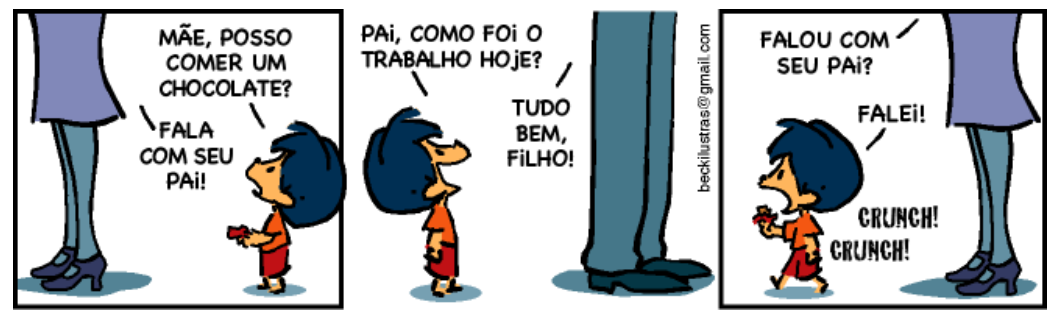

Figura 3 - Tirinha 3

Fonte: https://tirasarmandinho.tumblr.com/post/104193128309/tirinha-original

Nesse último exemplo, a primeira fala da tirinha constitui-se de frase interrogativa que expõe o pedido do menino; e a segunda frase configura-se como imperativa, indicando-lhe uma condição para comer o doce. Ambos os enunciados são caracterizadas por constituírem tentativas de fazer seus ouvintes tomarem atitudes responsivas a partir do que é dito, enquadrando-se, portanto, como sequências injuntivas. No segundo quadrinho, a pergunta do menino caracteriza-se, dentro do escopo das tipologias, como sequência injuntiva, pois pressupõe o posicionamento do interlocutor a partir do que é requerido. Já a resposta do pai constitui-se em colocação dele sobre o dia de trabalho, 
fugindo à intencionalidade inicial da pergunta da mãe, refletindo-se como uma articulação do menino para obter o que queria. A pergunta da mãe, no terceiro quadrinho, também, constitui uma imperativa, pressupondo a colocação do garoto sobre sua indagação inicial. A quebra da máxima do modo reside, então, na ambiguidade pressuposta pela ação de "falar" e está relacionada às intenções subjacentes a essa ação.

Tanto na fala de Armandinho para o pai, como na da mãe, o diretivo propõe-se a fazer questionamentos mais tênues. Entretanto, quando o diretivo se propõe a impor (caso da imperativa usada pela mãe, no primeiro quadrinho), há uma sobreposição de forças ilocucionárias, pois a emotividade realça papéis, tanto da exclamativa quanto da imperativa. Nesse caso, as duas forças ilocucionárias expõem sequências tipológicas que podem estar coadunadas ao plano do narrar, na exposição de uma fala carregada de emotividade e expressão; ou, ainda, do plano argumentativo, quando a fala da mãe expõe sobre uma tentativa de forçar o menino a fazer algo.

Com o intuito de analisar os efeitos de sentido que a tirinha geraria nos participantes, propusemos as questões apresentadas no quadro 4, no qual apresentamos, também, as repostas dos estudantes.

\begin{tabular}{|l|l|l|l|}
\hline \multicolumn{1}{|c|}{ Questões } & $\begin{array}{l}\text { 1) O que a mãe de } \\
\text { Armandinho esperava dele? }\end{array}$ & $\begin{array}{l}\text { 2) Que pergunta a mãe } \\
\text { de Armandinho deveria } \\
\text { ter feito, para leva-lo ao } \\
\text { diálogo esperado com } \\
\text { seu pai? }\end{array}$ & $\begin{array}{l}\text { 3) Onde está o humor da } \\
\text { tirinha? }\end{array}$ \\
\hline Qespostas & $\begin{array}{l}\text { Que ele pedisse permissão ao } \\
\text { pai ipara comer chocolate }\end{array}$ & $\begin{array}{l}\text { "Como será que foi o dia } \\
\text { de seu pai, Armandinho?" }\end{array}$ & $\begin{array}{l}\text { Na pergunta que o Armadinho } \\
\text { fez para o pai. }\end{array}$ \\
\hline QMC_02 & $\begin{array}{l}\text { Que ele fosse ao pai e o } \\
\text { pedisse para comer o } \\
\text { chocolate }\end{array}$ & $\begin{array}{l}\text { Que ele fosse ao pai e o } \\
\text { pedisse para comer } \\
\text { chocolate }\end{array}$ & $\begin{array}{l}\text { Ela esta no quadrinho 2 e 3, } \\
\text { onde ele fala com o pai mas não } \\
\text { o pede para comer o chocolate, } \\
\text { como sua mae o havia pedido } \\
\text { para ele fazer. }\end{array}$ \\
\hline QMC_03 & $\begin{array}{l}\text { Que ele fosse perguntar ao } \\
\text { pai se ele poderia comer um } \\
\text { chocolate }\end{array}$ & $\begin{array}{l}\text { Ela deveria ter falado para } \\
\text { ele ir perguntar ao pai se } \\
\text { poderia comer chocolate. }\end{array}$ & $\begin{array}{l}\text { Ele achar que deveria apenas ir } \\
\text { falar com o pai em vez de pedir } \\
\text { para comer um chocolate. }\end{array}$ \\
\hline QMC_04 & $\begin{array}{l}\text { Que ele pedisse permissão ao } \\
\text { seu pai. }\end{array}$ & "Pessa ao seu pai" & No último quadro. \\
\hline
\end{tabular}

\section{Quadro 4 - Respostas dos estudantes}

Fonte: Fragmentos dos enunciados elaborados pelos participantes da pesquisa.

As respostas sugerem que, ainda que a mãe omita uma expressão, continua claro que o assunto a ser tratado com o pai é a permissão para comer o chocolate, como mostram QMC_02: "Que ele fosse perguntar ao pai se ele poderia comer um chocolate" e QMC_04: “Que ele pedisse permissão ao seu pai.”. Nessa perspectiva, defende-se que as escolhas lexicogramaticais interferem no entendimento de uma fala/texto/enunciado. Sobre isso, destacamos que quatro dos quatro estudantes alterariam a escolha do verbo e apenas um faria uma seleção linguística que corroboraria o entendimento do Armandinho: (QMC_01) “Como será que foi o dia de seu pai, Armandinho?” 
Novamente, os participantes demonstraram entender adequadamente o humor a tirinha, conforme se vê: QMC_01: "Na pergunta que o Armadinho fez para o pai." e QMC_04: "No último quadro.”. Destaca-se, porém, QMC_02: "Ela esta no quadrinho 2 e 3, onde ele fala com o pai mas não o pede para comer o chocolate, como sua mãe o havia pedido para ele fazer.", que explicita que a primeira fala da mãe consta de um ato diretivo na medida em que ela esperava uma determinada atitude do personagem.

Em última análise, percebemos que a quebra da máxima do modo relaciona o material (linguístico) ao intencional (discursivo), dentro da perspectiva pragmática. Ao proferir as sequências injuntivas, a mãe de Armandinho, ao mesmo tempo, impõe e argumenta, e, nesse último caso, não encontra adesão do personagem do menino.

\subsection{BREVE DISCUSSÃO: A SOBREPOSIÇÃO TIPOLÓGICA}

Após findar a etapa sobre as questões linguístico-discursivas das tirinhas, a última parte da atividade constou de perguntas mais abrangentes quanto às máximas conversacionais observadas nas tirinhas. Estão representadas no quadro 5, a seguir.

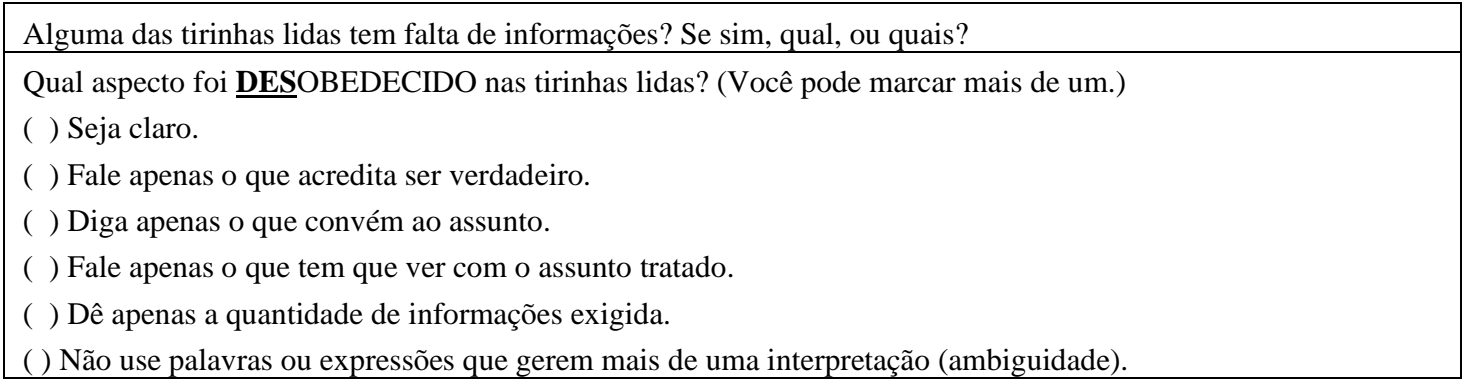

\section{Quadro 5 - Perguntas aos estudantes}

Fonte: Fragmentos dos enunciados elaborados pelos participantes da pesquisa.

Quando perguntados sobre qual ou quais regras das máximas conversacionais foi ou foram quebradas, foi unânime a escolha daquela em que se alicerça a clareza. Além dessa máxima, dois dos quatro participantes assinalaram a ambiguidade e, por último, um deles selecionou "diga apenas o que convém" e "fale apenas o que tem que ver com o assunto". Essas respostas sugerem que os alunos entendem que, para que os sentidos sejam assumidos na comunicação, certas regras precisam ser acolhidas pelos interagentes. A quebra dessas regras, ainda que implícitas, pode ser fonte de descompassos inerentes ao entendimento dos sentidos, gerando falhas na interpretação do texto. A exemplo disso, os estudantes reconheceram que a ambiguidade, como na questão 3 do primeiro exemplo ("o que gera humor na tirinha"), concretiza a quebra da máxima do modo, pois revela a necessidade de se deixar claro que o menino ficaria de castigo se não fizesse a tarefa ordenada.

Apenas um participante não considerou haver falta de informações nas três tirinhas. Os outros quatro sujeitos entenderam que a segunda tirinha, a da pichação, constrói-se nessa falta de informação. Vale destacar que nenhum dos alunos considerou haver falta de informação na tirinha número 1, geradora de ambiguidade pela escolha do pronome; 
nem na terceira tirinha, em que o assunto está implícito na fala da mãe de Armandinho: "Vá falar [sobre o chocolate] com seu pai". Antes, os quatro sujeitos que entenderam haver falta de informações identificaram que apenas a tirinha 2 constrói-se nessa falta, como se vê em QMC_01 "Sim, a tirinha no [2]" e em QMC_02 “Apenas a número [2], na minha opinião". Nesse caso, os participantes não interpretaram os sentidos mais profundos da tirinha, restando, cognitivamente, presos às ideias respaldadas pelo sentido denotativo das expressões linguísticas.

Se, por um lado, a composição do corpus evidencia o componente pragmático comum às interações do personagem Armandinho e seus interlocutores, mostrando princípios comuns à intencionalidade comunicativa, por outro lado essas interações podem denotar algumas considerações a respeito da predominância argumentativa como marca tipológica dessas tirinhas. Assim, ocupamo-nos, doravante, da forma como os alunos associam as questões pragmáticas ao aspecto argumentativo dos fatos narrados ainda que eles não tenham conhecimentos técnicos a respeito das teorias levantadas.

A predominância argumentativa pode ser constatada ao assumir-se que as ações subjacentes às frases propõem-se a narrar a troca comunicativa dos personagens, mas visam, principalmente, ao convencimento do outro. E é nesse sentido que a tirinha 1 revela uma mãe que pretende fazer com que seu filho, uma criança, arrume seu quarto. Ao pretender impor, por meio da ameaça, ela estaria, também, argumentando com ele, ao dar-lhe subsídios à refutação desses argumentos mediante uma fala indireta. Neste evento linguístico, os sujeitos não perceberam tal nuança, o que nos leva a interpretar uma falta de maturidade no entendimento de perguntas indiretas, quando essas se propõem a serem burladas pelo personagem Armandinho.

O mesmo ocorreu na tirinha 2, quando a mãe pergunta ao menino o que era "aquilo" na parede. Nessa etapa da atividade, apenas um dos participantes demonstrou depreender a repreensão subjacente à pergunta da mãe, que subentendia mudança de postura. Os demais estudantes sinalizaram uma carga denotativa na pergunta da mãe, o que nos leva a interpretar, mais uma vez, que esses alunos do nono ano parecem não estar prontos para considerar certos recursos linguísticos com fins argumentativos.

$\mathrm{Na}$ tirinha 3, o teor argumentativo parece ficar mais evidente para os alunos, que demonstraram perceber a intenção da mãe de Armandinho de convencê-lo a algo. Contudo percebemos que isso ocorreu porque a mãe deu uma ordem expressa ("Vá falar com seu pai"). Entendemos, com isso, que a argumentatividade parece estar presente no conhecimento desses alunos em nível mais autoritário, subjacente à injunção, sem considerar a argumentação em si. Isso reflete, portanto, a sutileza do convencimento, marca do tipo argumentativo e, por consequência, torna a Tirinha um bom exemplar para o desenvolvimento da leitura de recursos que se propõem à argumentação.

Essa falta de entendimento pode ser explicada quando os estudantes, ao analisar a sobreposição de atos de fala diretivos que não exercem efeitos no comportamento de Armandinho, não identificam a intenção da fala da mãe, que é o convencimento - essência da argumentação. Revelaram não considerar, com isso, que perguntas, frases exclamativas e asserções podem pressupor ordens a serem obedecidas, refletindo a argumentação subjacente a essas narrativas - análise que revela a necessidade de leituras e de atividades baseadas em textos que se utilizem desse tipo de recurso. 
Nas respostas relacionadas ao humor presente nas tirinhas, percebemos que o fato linguístico visto na materialidade textual foi adequadamente trabalhado com esses alunos, a ponto de a) perceberem escolhas advindas das classes de palavras; e b) sugerirem substituições pautadas na lexicogramática. No entanto, vimos que essas escolhas se fixaram nas representações gramaticais da língua, limitando o sentido depreendido ao valor (supostamente) primário dos termos. Isso porque, nas respostas relacionadas ao teor argumentativo das tirinhas, os alunos só perceberam os sentidos emanados das ordens diretas ou dos sentidos primários das palavras.

Essa análise direciona-nos ao projeto de ensino da língua constante nos PCNs e nos demais estudiosos citados no aporte teórico: um ensino que pense a superfície linguística do texto concomitantemente com seus sentidos possíveis; um ensino que se valha das diversas possibilidades expressivas da língua, em cada um de seus recursos lexicogramaticais, mas que avance da gramática para o discurso. No contexto específico dos geradores dos dados da pesquisa realizada, são estudantes que convivem com o contexto de violência e abandono das autoridades. Convivem no contexto de falta. Ainda assim, suas respostas demonstram que a escola e os contextos discursivos em que se inserem propiciam desenvolvimento sobre as questões pragmáticas da linguagem, podendo, portanto, ser mais desenvolvido o domínio da sobreposição tipológica.

\section{CONSIDERAÇÕES FINAIS}

Os principais resultados sugerem que, conquanto os sujeitos participantes da pesquisa não conheçam a terminologia proposta por Paul Grice, eles compreendem que a quebra das máximas conversacionais pode ser utilizada como recurso expressivo, visando, assim, à geração de humor. A análise mostra, também, que os participantes perceberam que essa quebra se deu na materialidade linguística do texto especificamente nas escolhas morfológicas, o que reforça resultados de trabalhos anteriores que pregam a integração texto-gramática no ensino da língua, (GULART, 2014). Os resultados indicam, por fim, que a argumentatividade presente nas tirinhas não foi percebida por esses alunos em um constructo linguístico intencional.

A sugestão do trabalho com texto por meio do gênero tirinha responde a várias pesquisas e orientações centradas nas mudanças paradigmáticas, nas últimas décadas, relacionadas ao ensino. Trata-se de mudanças materializadas tanto nos componentes curriculares quanto na forma de interação com o texto/língua(gem), mas, principalmente, com o texto/língua/sujeito/contexto em sala de aula.

Essas demandas influenciaram nossa opção pelas tirinhas do Armandinho, que, comumente utilizadas no processo pedagógico, atendem ao gosto dos alunos adolescentes. No sentido mais estritamente linguístico, essas tirinhas possuem riqueza expressiva, ativando conhecimentos mais elaborados para sua interpretação. Assim sendo, podem ser instrumento tanto para a descrição linguística quanto para aplicação no ensino de língua materna. Para a investigação, valemo-nos de dois de seus recursos: a ambiguidade reconhecida como geradora do humor das tirinhas; e a possível sobreposição tipológica. 
As atividades sugeridas a partir da leitura de três tirinhas de Armandinho visaram investigar a forma como quatro estudantes perceberiam a construção do humor das narrativas. Além do humor, pudemos observar a sequência textual de base argumentativa, que é peculiar ao estilo do produtor desses textos, e que pode ser observada na análise do ato ilocucionário - mediante a intencionalidade intrínseca às falas dos personagens.

Entendemos que tanto a teoria dos atos de fala (AUSTIN, 1962; SEARLE, 1969) como o estudo das máximas conversacionais (GRICE, 1984) podem prover instrumentos analíticos eficientes para propor atividades que potencializem a leitura de gêneros híbridos em linguagem e em recursos estilísticos. Isso se viu, especialmente, nas respostas dos alunos, que perceberam que o humor das tirinhas se gera na quebra da máxima do modo.

Contudo, em um contexto analítico maior, o da sobreposição tipológica (marcada, na investigação, pela intencionalidade da mãe, de convencer Armandinho), constitui habilidade de leitura que precisa ser fomentada. Ambas as tipologias, a narrativa e a argumentativa, apontam para a tirinha como instrumento analítico das construções tipológicas respaldáveis pelo viés pragmático, e que esse componente estimula mais perspicácia por parte dos alunos para o seu entendimento.

Por fim, não se pretende sugerir uma prática pedagógica que faça uso da nomenclatura exposta, para que não se incida no ensino pela metalinguagem; antes, sugere-se que o teor pragmático possa ser vindicado aos estudantes de forma que possam trabalhar com e sobre a linguagem. Para isso, entendemos a relevância do conhecimento de teorias como as utilizadas, por parte dos professores, como forma de ferramenta científica para uma ensino coerente com as sugestões de ensino com gêneros.

\section{REFERÊNCIAS}

ADAM, J. M. A linguística textual: uma introdução à análise textual dos discursos. 2. ed. revista e aumentada. São Paulo: Cortez, 2011.

ALDROVANDI, M. A construção do humor pelo cancelamento de implicaturas. Revista Percursos Linguísticos, v. 5, n. 11, p. 8162-8174, 2015.

ALVEZ-MAZZOTTI, A. J. . O debate contemporâneo sobre os paradigmas. In: ALVEZ-MAZZOTTI, A. J., GEWANDSZNAJDER, F. O método nas ciências naturais e sociais: Pesquisa quantitativa e qualitativa. 2. ed. São Paulo: Pioneira, 1999. p.129-145.

AUSTIN, J. L. How to do things with words. Cambridge, Massachusetts: Harvard University Press, 1962.

BAKHTIN, M. M. Estética da criação verbal. São Paulo: Martins Fontes, 1997.

BECK, A. Tirinhas do Armandinho. Disponível em:

http://tirasarmandinho.tumblr.com/post/104193128309/tirinha-original. Acesso em: 5 maio 2016.

BRASIL. Parâmetros Curriculares Nacionais (PCN). Introdução. Ensino Fundamental. Brasília MEC/SEF, 1998, vol.1. Disponível em http://portal.mec.gov.br/seb/arquivos/pdf/livro01.pdf. Acesso em: 4 maio 2015.

BRASIL. Ministério da Educação. Lei de Diretrizes e Bases da Educação Nacional. Lei n. 9.394/96. Disponível em: http://www.planalto.gov.br/ccivil_03/Leis/L9394.htm. Acesso em: 10 jun. 2016.

BRONCKART, J. P.. Atividade de linguagem, textos e discursos: por um interacionismo sociodiscursivo. São Paulo: Educ, 2012. 
DENZIN, N. K; LINCOLN, I. S. O. Introdução: a disciplina e a prática da pesquisa qualitativa. In: DENZIN, N. K; LINCOLN, I. S. O. (Org.). O planejamento da pesquisa qualitativa: teorias e abordagens. 2. ed. Porto Alegre: Artmed, 2006. p. 15-41.

FERREIRA, H. R. M. Os atos de fala nos textos instrucionais: Uma proposta de leitura a partir da perspectiva interlocutiva. 2013. 296 f. Tese (Doutorado em Letras) - Programa de Pós-graduação em Letras, Universidade do Estado do Rio de Janeiro, Rio de Janeiro, 2013.

GRICE, Paul. Logic and conversation. In: DASCAL, M. (Org.). Fundamentos metodológicos da linguistica: pragmática. Campinas: Editora do Autor, v. 4, p. 81-103, 1982.

GULART, K. D. S. A. A prática de análise linguística: estratégias de diálogo com os gêneros do discurso no livro didático. 2010. 131f. Dissertação (Mestrado em Linguística) - Programa de Pós-graduação em Linguística, Universidade Federal de Pernambuco, Recife, 2010.

KLEIMAN, A. Letramento e suas implicações para o ensino de língua materna. Signo, Santa Cruz do Sul, v. 32, n. 53, p. 1-25, dez. 2007.

KOCH, I. V. A inter-ação pela linguagem. 2. ed. São Paulo: Contexto, 1995.

KOCH, I. V. Desvendando os segredos do texto. 7. ed. São Paulo: Cortez, 2011.

MARCUSCHI, L. A. Gêneros textuais: definição e funcionalidade. In: DIONÍSIO, A. P.; MACHADO, A. R.; BEZERRA, M. A. (Org.). Gêneros textuais e ensino. 5. ed. Rio de Janeiro: Lucerna, 2007, p. 1936.

MARCUSCHI, L. A. Produção textual, análise de gêneros e compreensão. São Paulo: Parábola Editorial, 2008.

MARCUSCHI, B. Escrevendo na escola para a vida. In: RANGEL, E. de O.; ROJO, RODRIGUES, R. H. (Org.). Língua Portuguesa: ensino fundamental. Vol. 19. Brasília: Ministério da Educação, Secretaria de Educação Básica, 2010. p. 65-84. (Coleção Explorando o Ensino).

PRODANOV, C. C; FREITAS, E. C. 2. ed. Metodologia do trabalho científico - Métodos e Técnicas da Pesquisa e do Trabalho Acadêmico. Novo Hamburgo: Feevale, 2013.

RAJAGOPALAN, K. Nova pragmática: fases e feições de um fazer. São Paulo: Parábola Ed., 2010.

RAMOS, P. Tira ou tirinha? Um gênero com nome relativamente instável. Estudos Linguísticos, São Paulo, v. 42, n. 3, p. 1281-1291, set.-dez. 2013.

SEARLE, J. Speech acts: an essay in the philosophy of language. New York: Cambridge University Press, 1969.

SEARLE, J. Os actos de fala: um ensaio de filosofia da linguagem. Coimbra: Livraria Almedina, 1981.

SEARLE, J. Expressão e significado: estudo da teoria dos atos de fala. 2. ed. São Paulo, Martins Fontes, 2001.

SILVA, J. Q. G. Gênero discursivo e tipo textual. Scripta, v. 2, n. 4, 9, p. 87-106, 1999.

SOARES, M. Linguagem e escola. 17. ed. São Paulo: Ática, 2006.

TRAVAGLIA, L. C. Seleção e organização de informações e a produção de textos. In: DUARTE, L. P. Para sempre em mim: homenagem a Ângela Vaz Leão. Belo Horizonte: CESPUC, 1999. p. 197- 204.

VARGAS, S. L; MAGALHÃES, L. M. O gênero tirinhas: Uma proposta de sequência didática. Educ. Foco, Juiz de Fora, v. 16, n. 1, p. 119-143, mar./ago. 2011.

WEINRICH H. Estructura y función de los tiempos en el lenguaje. Madrid: Gredos, 1968.

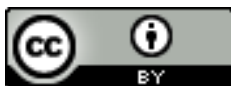

Este texto está licenciado com uma Licença Creative Commons Atribuição 4.0 Internacional.

FERREIRA, Hilma Ribeiro de Mendonça; GUIMARÃES, Silvia Adelia Henrique. Quebra de máximas conversacionais nas tirinhas do Armandinho: uma possibilidade metodológica para o ensino expressivo da língua. Linguagem em (Dis)curso - LemD, Tubarão, SC, v. 20, n. 2, p. 289-306, maio/ago. 2020. 